\title{
Designing high-temperature steels via surface science and thermodynamics
}

\author{
Cameron T. Gross ${ }^{1}$, Zilin Jiang ${ }^{1}$, Allan Mathai $^{2}$, Yip-Wah Chung ${ }^{1,2 *}$ \\ ${ }^{1}$ Department of Materials Science and Engineering, \\ ${ }^{2}$ Department of Mechanical Engineering, \\ Northwestern University, Evanston, IL 60208, USA \\ * Corresponding author: ywchung@northwestern.edu
}

Keywords Atom Probe Tomography; surface engineering; ferritic steels; CALPHAD

\begin{abstract}
Electricity in many countries such as the US and China is produced by burning fossil fuels in steam-turbine-driven power plants. The efficiency of these power plants can be improved by increasing the operating temperature of the steam generator. In this work, we adopted a combined surface science and computational thermodynamics approach to the design of hightemperature, corrosion-resistant steels for this application. The result is a low-carbon ferritic steel with nanosized transition metal monocarbide precipitates that are thermally stable, as verified by atom probe tomography. High-temperature Vickers hardness measurements demonstrated that these steels maintain their strength for extended periods at $700^{\circ} \mathrm{C}$. We hypothesize that the improved strength of these steels is derived from the semi-coherent interfaces of these thermally stable, nanosized precipitates exerting drag forces on impinging dislocations, thus maintaining strength at elevated temperatures.
\end{abstract}

\section{Introduction}

In the US, about $67 \%$ of the generated electricity is produced by burning fossil fuels, of which coal contributes about 39\% [1]. The corresponding numbers for China are 69\% and 63\% [2]. Burning of coal not only emits more carbon dioxide per kWh electricity produced compared with natural gas [3], but also particulates and other toxic pollutants such as mercury and arsenic [4]. Since it is unlikely for the US, China and other countries to stop burning fossil fuels to produce electricity in the foreseeable future, the most reasonable solution to mitigate $\mathrm{CO}_{2}$ and pollutant emission is to make power plants more efficient. US coal-fired power plants operate at an average efficiency of $32 \%$, emitting about $1000 \mathrm{gm} \mathrm{CO}_{2}$ per $\mathrm{kWh}$ electricity produced. According to the World Coal Association, if one can raise the efficiency to $50 \%$, the $\mathrm{CO}_{2}$ emission will be reduced to about $700 \mathrm{gm}$ per $\mathrm{kWh}$ [5].

One can increase the thermal efficiency of these power plants by operating the steam generator at higher temperatures (and pressures). Most steam turbines in the US operate at $540^{\circ} \mathrm{C}$ or below, and the proposed target by the US Department of Energy is to increase the operating temperature to $760^{\circ} \mathrm{C}$. Extensive research studies are being conducted on the use of Ni-based superalloys for such applications, and results are quite promising [6]. The only drawback is the cost of the superalloys, about $\$ 30-40 / \mathrm{kg}$ in 2015 . An alternative is to explore the use of high-performance steels in steam generators that can maintain $35 \mathrm{MPa}$ strength for 100,000 hours at 600 to $625^{\circ} \mathrm{C}$. In this initial study, we will focus on meeting the $600^{\circ} \mathrm{C}$ temperature goal through accelerated aging tests at $700^{\circ} \mathrm{C}$. 
Strength of structural steels is normally achieved by four methods: solid solution strengthening, strain hardening, grain refinement, and precipitates [7]. For the purpose of this discussion, let us focus on precipitates, which act as obstacles against dislocation motion, thus providing strength to the steel. Precipitate strengthening scales roughly as the inverse of the spacing between these precipitates. Extended operation at elevated temperatures results in coarsening of these precipitates (Ostwald ripening) and hence increased spacing between precipitates [8]. Therefore, the first-order solution to having steels with adequate strength for extended high-temperature operations is to incorporate thermally stable precipitates in steels.

\section{Design Approach}

\subsection{Precipitate structure}

In the early stage of precipitate growth and assuming interfacial kinetics controlled growth, the growth velocity $v$ of a precipitate due to arrival of solute atoms from the matrix to the precipitate surface is given by [9]:

$$
v \propto \exp \left(-\Delta f_{m} / k T\right)\left[1-\exp \left(-\Delta f_{m p} / k T\right)\right]
$$

where $\Delta f_{m}$ is the activation energy for the migration of the solute atom from the matrix to the precipitate, $\Delta f_{m p}$ free energy difference between the solute atom in the matrix and precipitate, $k$ the Boltzmann constant, and $T$ temperature. $\Delta f_{m p}$ contains an interfacial energy term; the sign of $\Delta f_{m p}$ is such that a coherent matrix-precipitate interface makes $\Delta f_{m p}$ more positive, resulting in a higher growth rate. This implies that just nucleated precipitates should be coherent with the matrix. Upon further aging, precipitates coarsen through an Ostwald ripening process, i.e., larger precipitates growing at the expense of smaller ones. This process is described well by the LSW equation [10], i.e.,

$$
R(t)^{3}-R_{o}^{3} \propto \gamma D\left(t-t_{o}\right)
$$

where $R(t)$ is the precipitate radius at time $t, R_{o}$ precipitate radius at $t_{o}, D$ diffusivity of the solute atom, and $\gamma$ the interfacial free energy. This equation indicates that coherent precipitates with low interfacial free energy and made of slow diffusing elements will grow slower than incoherent ones.

One suitable candidate for such precipitates is $\mathrm{NiAl}$, which has a $\mathrm{B} 2(\mathrm{CsCl})$ structure with a lattice constant of $0.289 \mathrm{~nm}$. This is virtually identical to that of bcc Fe $(0.287 \mathrm{~nm})$. Indeed, NiAl is being studied as a viable precipitate for high-temperature steels [11]. Another candidate is MC, transition metal monocarbide with the $\mathrm{B} 1(\mathrm{NaCl})$ structure, $\mathrm{VC}$ and $\mathrm{NbC}$ being two such examples. Lattice constants of $\mathrm{VC}$ and $\mathrm{NbC}$ are 0.417 [12] and $0.447 \mathrm{~nm}[13,14]$ respectively. These carbide precipitates will form with a Baker-Nutting orientation on the bcc iron lattice [15, 16]. The length of the unit vector along the [110] direction of bcc Fe is $0.287 \times 2^{1 / 2}=0.406 \mathrm{~nm}$. Therefore, on the (001) plane, $\mathrm{MC}$ is coherent with $\mathrm{Fe}\left(45^{\circ}\right.$ rotation) with lattice mismatch of $2.7 \%$ for $\mathrm{VC}$ and $10.1 \%$ for $\mathrm{NbC}$. Along the [010] direction, $\mathrm{MC}$ is commensurate with $\mathrm{Fe}$ (two unit cells of MC matching three unit cells of $\mathrm{Fe}$ ) with lattice mismatch of $3.3 \%$ for $\mathrm{VC}$ and 
$10.1 \%$ for $\mathrm{NbC}$. Therefore, in order for the MC precipitate to form coherent interfaces with the Fe matrix to achieve low interfacial energy, the system has to pay a strain energy penalty. Minimization of the total free energy results in the MC precipitate forming a coherent or semicoherent interface, as shown in Fig. 1.

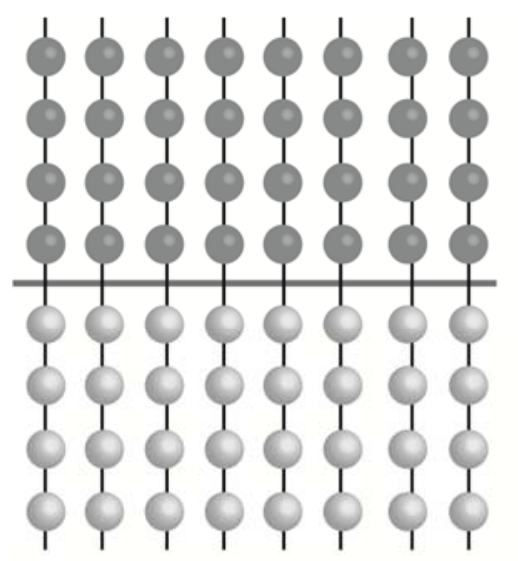

Coherent

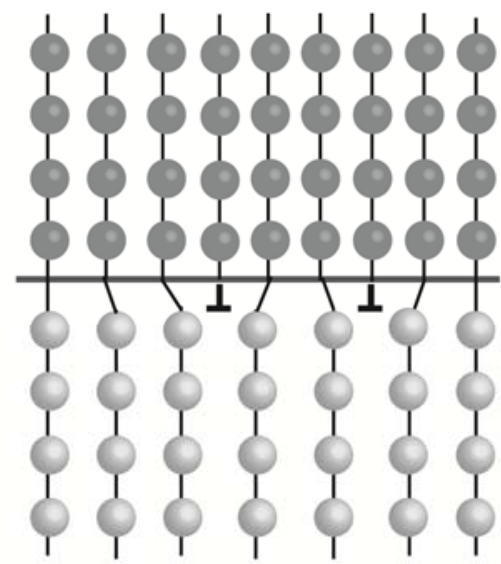

Semi-coherent

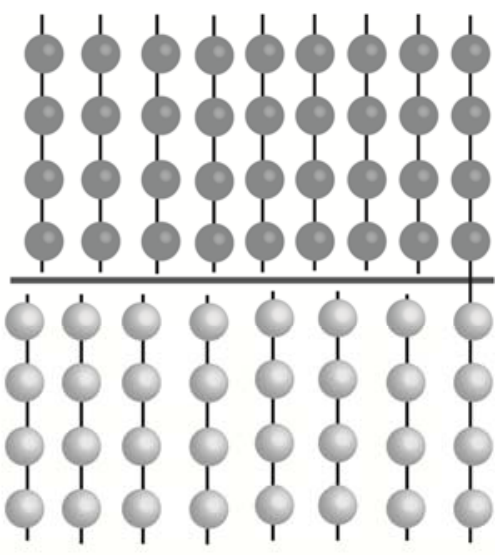

Incoherent

Figure 1: Schematic examples of different interface types

The semi-coherent interface formed between $\mathrm{MC}$ precipitates and the $\mathrm{Fe}$ matrix is not necessarily a disadvantage. At elevated temperatures, precipitates become less effective obstacles against dislocation climb due to thermal activation. However, it has been shown [17-19] that a semi-coherent precipitate-matrix interface has an attractive interaction with an impinging dislocation. Fig. 2 shows a dislocation bypassing a spherical precipitate as it sweeps over its surface. As the dislocation sweeps over the precipitate, the attractive interaction by the semicoherent precipitate-matrix interface exerts a drag on the dislocation, reducing its mobility and maintaining the alloy strength even at elevated temperatures.

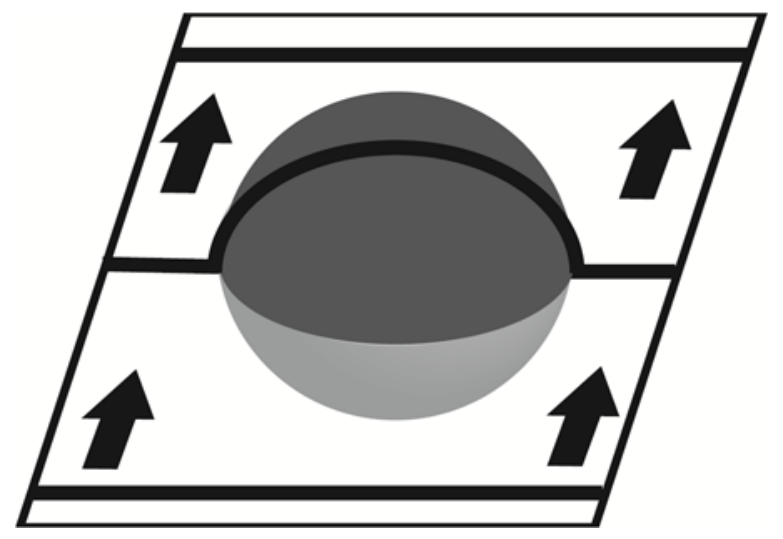

Figure 2: Depiction of a line dislocation bypassing a spherical precipitate

\subsection{Computational thermodynamics modeling}

In addition to $\mathrm{Fe}$, plain carbon steels contain $\mathrm{C}, \mathrm{Si}$, and $\mathrm{Mn}$, the latter two elements added for the purpose of deoxidation and scavenging of residual sulfur respectively [20]. In this work, four 
additional alloying elements will be considered: $\mathrm{Cr}$ for corrosion protection, Mo for slower diffusion, $\mathrm{Nb}$ and $\mathrm{V}$ for the formation of $\mathrm{MC}$ precipitates. We used computational thermodynamics to select the appropriate steel composition with the objective to maximize the phase fraction of MC, especially at elevated temperatures. Commercial software (Thermo-Calc) was used with the SGTE Solutions Database version 2.1 (SSOL2). The Scientific Group Thermodata Europe developed the SGTE/SSOL2 database. For simplicity, we will present only the weight percentage of $\mathrm{Cr}$ and $\mathrm{V}$. An example of one such computation for a low-carbon steel is illustrated in Fig. 3 (a), which shows a vanadium isopleth for steel composition containing $10 \mathrm{Cr}-\mathrm{xV}$ (in wt. \%). When the $\mathrm{V}$ concentration is greater than or equal to $1.0 \mathrm{wt} . \%, \mathrm{MC}$ is the only stable precipitate phase between 600 and $800^{\circ} \mathrm{C}$. More important, the equilibrium concentration of complex carbide $\mathrm{M}_{23} \mathrm{C}_{6}$ steadily decreases with increasing $\mathrm{V}$ concentration, while the MC phase fraction increases, as shown in Fig. 3(b) and 3(c). At sufficiently high V concentration, the $\mathrm{M}_{23} \mathrm{C}_{6}$ carbide phase disappears above a certain temperature. $\mathrm{M}_{23} \mathrm{C}_{6}$ is not a desirable phase because it is not stable against coarsening at elevated temperatures, so we seek to minimize the amount present in our alloys.
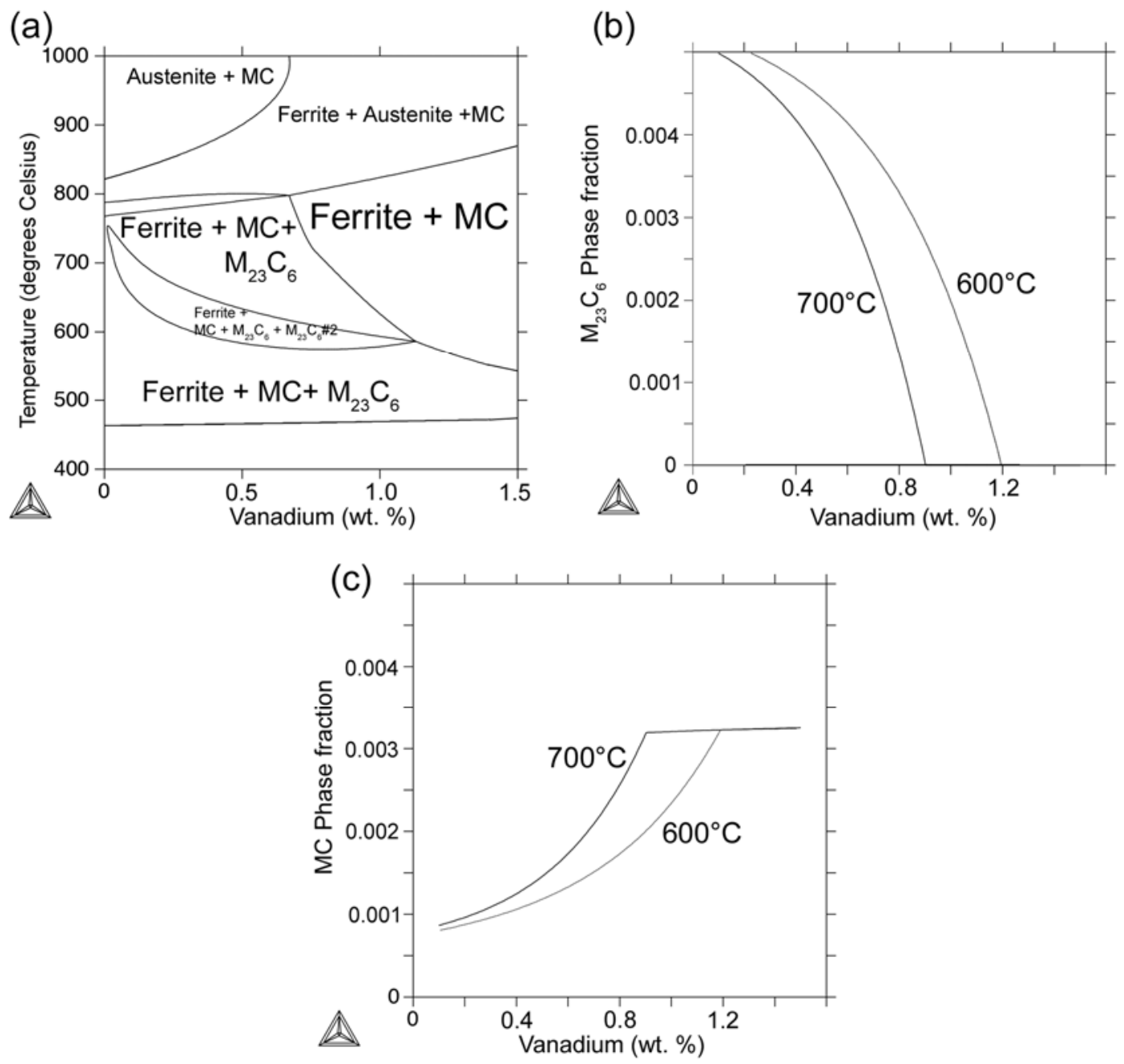

Figure 3: (a) Calculated $\mathrm{V}$ isopleth of low-carbon steel containing $10 \mathrm{wt} . \% \mathrm{Cr}$ and variable amounts of $\mathrm{V}$, (b) $\mathrm{M}_{23} \mathrm{C}_{6}$ phase fraction at $600^{\circ} \mathrm{C}$ and $700^{\circ} \mathrm{C}$ versus $\mathrm{V}$ concentration. (c) $\mathrm{MC}$ phase fraction vs $\mathrm{V}$ concentration. 
Figure 3(a) also shows that over the range of vanadium composition shown, the $\mathrm{M}_{23} \mathrm{C}_{6}$ phase is completely dissolved above $800^{\circ} \mathrm{C}$. Sufficiently rapid cooling may suppress the formation of this undesirable carbide during the manufacturing process.

\section{Experimental Methods}

Fabrication of the experimental steels was done through vacuum arc melting of $11 \mathrm{~g}$ ingots with the desired composition. Each ingot was inverted 4 times during melting to ensure homogeneity throughout the sample. All samples were normalized for one hour at $975^{\circ} \mathrm{C}$ after arc melting and then air-cooled. Microstructures of selected samples were observed using an optical microscope before and after aging treatment at elevated temperatures. Samples were ground flat using carbide grinding paper, and final polishing was done with $1 \mu \mathrm{m}$ diamond suspension. Samples were then etched using a $2 \%$ nital solution to reveal grain boundaries.

Mechanical properties were evaluated using Vickers indentation at $700^{\circ} \mathrm{C}$ in partial vacuum (pressure $<20 \mathrm{~Pa}$ ). The applied load was $1 \mathrm{kgf}$. Samples were ground flat and polished with 1 $\mu \mathrm{m}$ diamond suspension prior to hardness testing.

Atom probe tomography (APT) was used to study the formation and evolution of precipitate size and composition during aging at elevated temperatures. Samples were machined into $300 \mu \mathrm{m} \mathrm{x}$ $300 \mu \mathrm{m} \times 12.7 \mathrm{~mm}$ rectangular blanks. The blanks were then electropolished to a sharp tip using two different electrolytes: $5 \%$ perchloric acid in acetic acid for neck formation and 2\% perchloric acid in butoxyethanol for final polishing. Atom evaporation was conducted using voltage ramped from $0 \mathrm{~V}$ to approximately $7 \mathrm{kV}$, and evaporation was assisted by $20 \mathrm{pJ} \mathrm{UV}$ laser pulses at 500 $\mathrm{kHz}$. The voltage was controlled to maintain a constant evaporation rate. Data analysis was conducted using the Integrated Visualization and Analysis Software (IVAS) software suite developed by CAMECA [21].

\section{Results and Discussion}

Three experimental steels explored in this study: $0 \mathrm{Cr}-0.19 \mathrm{~V}, 10 \mathrm{Cr}-0.3$, and $10 \mathrm{Cr}-0.9 \mathrm{~V}$. All steels have approximately the same $\mathrm{C}, \mathrm{Mo}, \mathrm{Nb}, \mathrm{Mn}$, and $\mathrm{Si}$ content. $0 \mathrm{Cr}-0.19 \mathrm{~V}$ is the reference alloy without $\mathrm{Cr}$. $10 \mathrm{Cr}-0.3 \mathrm{~V}$ has sufficient $\mathrm{Cr}$ to make it corrosion-resistant in steam environments; the additional $\mathrm{V}$ promotes the formation of a larger phase fraction of $\mathrm{MC}$. $10 \mathrm{Cr}-0.9 \mathrm{~V}$ has an even higher fraction of $\mathrm{MC}$, and most importantly is calculated to have no $\mathrm{M}_{23} \mathrm{C}_{6}$ phase at $700^{\circ} \mathrm{C}$, as shown in Fig. 3(b).

Fig. 4 shows an optical micrograph of $0 \mathrm{Cr}-0.19 \mathrm{~V}$ before (a) and after (b) aging treatment at $600^{\circ} \mathrm{C}$ for 8 hours. The microstructure is characteristic of ferrite (bcc Fe) with small amounts of pearlite and bainite. After aging, only the ferrite phase remains. This is consistent with computational thermodynamics modeling that shows (ferrite $+\mathrm{MC}+\mathrm{M}_{23} \mathrm{C}_{6}$ ) as the stable phases at $600^{\circ} \mathrm{C}$ for this alloy composition. 


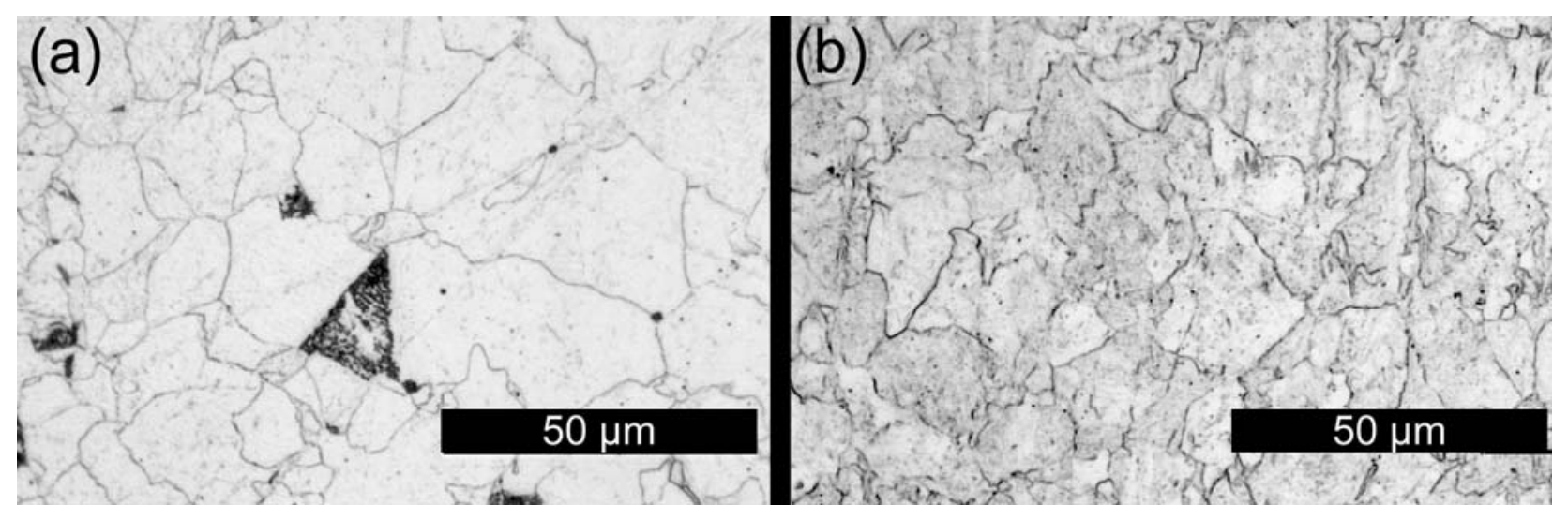

Figure 4: Optical micrographs of $0 \mathrm{Cr}-0.19 \mathrm{~V}$ (a) after air-cooling, (b) after aging at $600^{\circ} \mathrm{C}$ for 8 hours.

Fig. 5(a) shows an APT reconstruction of $0 \mathrm{Cr}-0.19 \mathrm{~V}$ after aging at $600^{\circ} \mathrm{C}$ for 27 hours, showing the presence of nanosized $(\mathrm{Nb}, \mathrm{V}) \mathrm{C}$ precipitates. Fig. 5(b) shows the growth of these precipitates as a function of time at $600^{\circ} \mathrm{C}$. Even after 27 hours, the average radius of these precipitates is only about one nm. This result demonstrates the thermal stability of the precipitates. Fig. 5(c) shows statistical distribution of $\mathrm{C} /(\mathrm{Nb}+\mathrm{V})$ ratio for precipitates. From this plot, it can be inferred that the precipitates are most likely a combination of the stable MC precipitates (ratio near 0.8), and metastable $\mathrm{M}_{2} \mathrm{C}$ precipitates (ratio near 0.5).

(a)

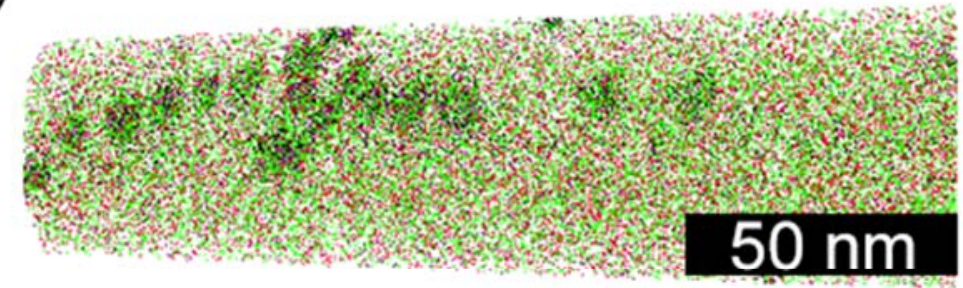

(c) (b)

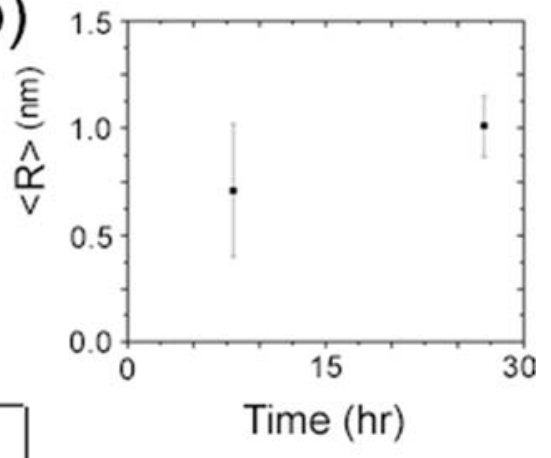

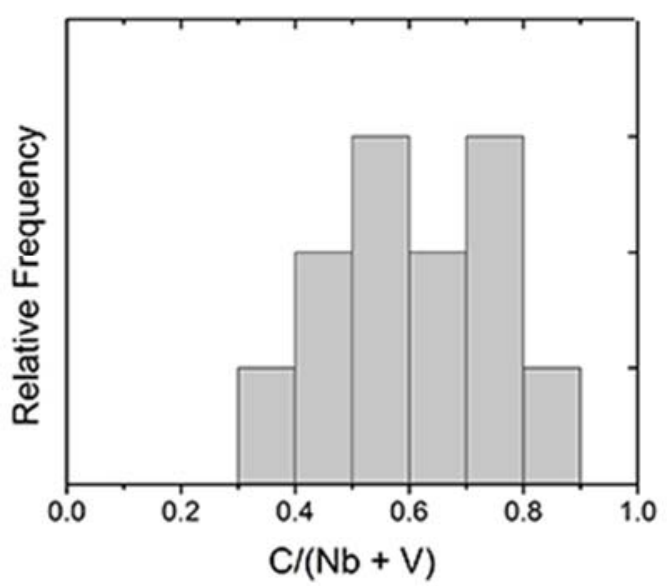

Figure 5: (a) APT reconstruction of $0 \mathrm{Cr}-0.19 \mathrm{~V}$ after aging at $600^{\circ} \mathrm{C}$ for 27 hours. For clarity, only $\mathrm{V}$ (green), $\mathrm{Nb}$ (purple), Mo (red) and $\mathrm{C}$ (black) atoms are shown. Nanosized carbide precipitates can be observed as the black clusters. (b) Average precipitate radius versus aging 
time at $600^{\circ} \mathrm{C}$. (c) Histogram of $\mathrm{C} /(\mathrm{Nb}+\mathrm{V})$ ratios of the precipitates after 27 hours of aging at $600^{\circ} \mathrm{C}$.

Fig. 6 shows the Vickers hardness (HV) of $0 \mathrm{Cr}-0.19 \mathrm{~V}$ steel measured at $600^{\circ} \mathrm{C}$ as a function of aging at $600^{\circ} \mathrm{C}$. There is an initial increase in hardness from 20 minutes to 8 hours, reaching a peak value of 105 , due to the nucleation of precipitates. From 8 to 100 hours, one observes a slight decrease of Vickers hardness, due to the slow growth and coarsening of these precipitates. The peak hardness of 105 corresponds to tensile strength of $343 \mathrm{MPa}$.

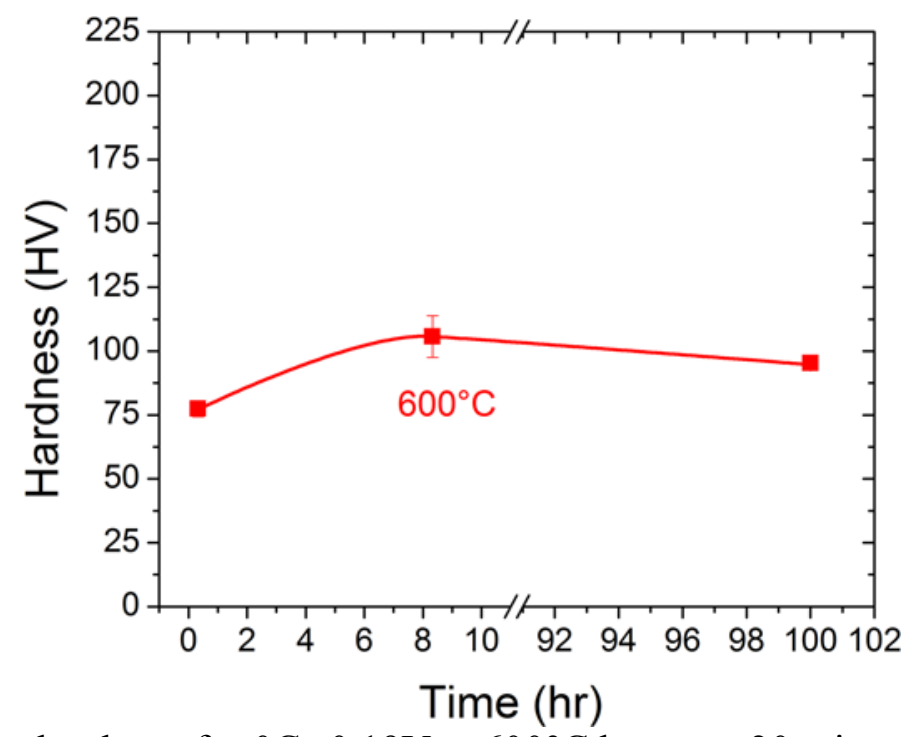

Figure 6: Vickers hardness for $0 \mathrm{Cr}-0.19 \mathrm{~V}$ at $600^{\circ} \mathrm{C}$ between 20 minutes and 100 hours.

Fig. 7 shows the Vickers hardness (measured at $700^{\circ} \mathrm{C}$ ) of all three experimental steels versus aging time at $700^{\circ} \mathrm{C}$. For $0 \mathrm{Cr}-0.19 \mathrm{~V}$ steel, its Vickers hardness is maintained up to 27 hours, beyond which the hardness decreases. In contrast, the hardness of $10 \mathrm{Cr}-0.3 \mathrm{~V}$ steel decreases slowly between 27 and 100 hours. An interesting observation is that the hardness of $10 \mathrm{Cr}-0.9 \mathrm{~V}$ continues to increase at 100 hours, achieving Vickers hardness of 38, or tensile strength of 124 $\mathrm{MPa}$. We believe this transient to be a consequence of the slower diffusion of alloying elements in the high $\mathrm{V}$ sample. The initial slight decrease in hardness is probably a combination of dislocation recovery, grain boundary and perhaps conversion of martensite to ferrite. As the steel continues to age, $\mathrm{MC}$ precipitates start to form, providing secondary strengthening. All these results are consistent with the fact that higher $\mathrm{V}$ promotes the formation of $\mathrm{MC}$ precipitates that are thermally stable and maintain strength at elevated temperatures. While not a perfect representation of coarsening rate, the observed trend would imply strength retention for longer times, which would seem to imply slower coarsening of these precipitates." 


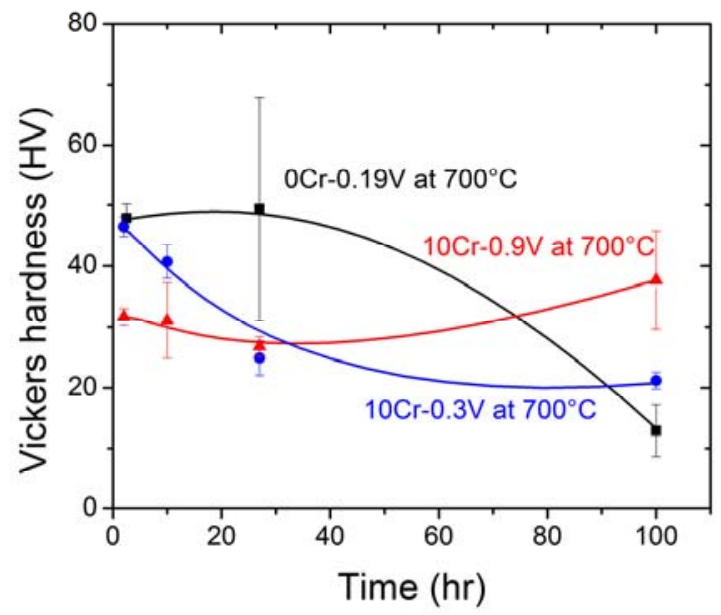

Figure 7: $700^{\circ} \mathrm{C}$ Vickers hardness for $0 \mathrm{Cr}-0.19 \mathrm{~V}$ (black), $10 \mathrm{Cr}-0.3 \mathrm{~V}$ (blue), and $10 \mathrm{Cr}-0.9 \mathrm{~V}$ (red) between 2 and 100 hours at $700^{\circ} \mathrm{C}$. The lines serve as guides for the eye.

Steels for steam generators in power plants are supposed to maintain $\geq 35 \mathrm{MPa}$ strength (Vickers hardness $\approx 10$ ) for at least 100,000 hours. Let us explore how our two Cr-based experimental steels perform relative to this requirement. For $10 \mathrm{Cr}-0.3 \mathrm{~V}$, the hardness decreases at the rate of 0.8 per hour between 0.3 and 27 hours at $700^{\circ} \mathrm{C}$, and 0.034 per hour between 27 and 100 hours. If we assume this rate to decrease further to 0.01 per hour beyond 100 hours, the hardness of $10 \mathrm{Cr}-0.3 \mathrm{~V}$ will decrease to 10 at 1250 hours. The coarsening of these MC precipitates is controlled by diffusion. In $b c c$ iron, the diffusion of carbon is rapid so that the coarsening of MC precipitates is controlled by the diffusion of the other two alloying elements, $\mathrm{Nb}$ and $\mathrm{V}$. The $\mathrm{Nb}$ diffusivity is given by $D=1.7 \times 10^{-3} \exp (-252000 / R T) \mathrm{m}^{2} \mathrm{~s}^{-1}$ [22], and that for $\mathrm{V}$ is given by $D=1.17 \times 10^{-4} \exp (-228040 / R T) \mathrm{m}^{2} \mathrm{~s}^{-1}$ [23]. The ratio of diffusivity at 700 to $600^{\circ} \mathrm{C}$ can be shown to be 35 for $\mathrm{Nb}$ and 25 for $\mathrm{V}$. Therefore, the extrapolated lifetime of $10 \mathrm{Cr}-0.3 \mathrm{~V}$ at $600^{\circ} \mathrm{C}$ is between 31,000 and 44,000 hours. Repeating this calculation for $10 \mathrm{Cr}-0.9 \mathrm{~V}$ gives the extrapolated lifetime at $600^{\circ} \mathrm{C}$ to be between 73,000 and 102,000 hours. While these lifetimes have to be confirmed with further accelerating testing, these initial results are encouraging and validate the combined surface science and computational thermodynamics approach to the design and development of high-performance alloys.

\section{Conclusion}

We adopted a combined surface science and computational thermodynamics approach in the design and development of Cr-based steels that produce thermally stable transition metal monocarbide (MC) precipitates at elevated temperatures. The design was based on the surface/interface science principle that semi-coherent $\mathrm{MC}$ precipitates consisting of slow diffusing elements tend to coarsen slowly and that such a semi-coherent precipitate-matrix interface exerts a drag force on impinging dislocations. Combined with computational thermodynamics, we designed two Cr-based steel compositions to maximize the volume fraction of such MC precipitates. These Cr-based steels were shown to maintain good strength for extended $700^{\circ} \mathrm{C}$ exposures and are thus suitable materials for use in steam generators in power plants for higher thermal efficiencies. 


\section{Acknowledgements}

The authors would like to acknowledge Prof. Morris E. Fine for many thoughtful discussions regarding dislocation drag, and Alyssa Zrimsek for aiding in the preparation of this manuscript. We also acknowledge the NSF CMMI division (Grant number NSF-CMMI-1130000) for providing partial funding for this. This work made use of Central Facilities supported by the MRSEC program of the National Science Foundation (DMR-0520513 and DMR-1121262) at the Northwestern University Materials Research Science and Engineering Center. APT was performed at the Northwestern University Center for Atom-Probe Tomography (NUCAPT). The LEAP was acquired and upgraded with equipment grants from the MRI program of the National Science Foundation and the DURIP program of the Office of Naval Research. Additional instrumentation at NUCAPT was supported by the Initiative for Sustainability and Energy at Northwestern (ISEN). 


\section{References}

[1] U.S. Energy Information Administration, May 2015 Monthly Energy Review, Washington, DC, pp. 102-110, (2015).

[2] U.S. Energy Information Administration, China International energy data and Analysis, Washington, DC, pg. 3, (2015).

[3] U.S. Energy Information Administration, How much carbon dioxide is produced per kilowatthour when generating electricity with fossil fuels? http://www.eia.gov/tools/faqs/faq.cfm?id=74\&t=11 (2015). [4] U.S. Environmental Protection Agency, Air Emissions, http://www.epa.gov/cleanenergy/energy-and-you/affect/air-emissions.html, (2014).

[5] World Coal Association, Cleaner coal technologies vital to reducing global CO2 emissions, http://www.worldcoal.org/extract/cleaner-coal-technologies-vital-to-reducing-global-co2emissions-5096/, (2015).

[6] Stam, A. F., Nextgenpower - Demonstration and component fabrication of nickel alloys and protective coatings for steam temperatures of $750^{\circ} \mathrm{C}$, Proceedings from the Seventh International Conference on Advances in Materials Technology for Fossil Power Plants (2013) 74-85.

[7] Chung, Y-W, Introduction to Materials Science and Engineering, CRC Press, 2006.

[8] Courtney, T, Mechanical Behavior of Materials, second ed., Waveland Press, Inc, Illinois, 2005.

[9] Reed-Hill, R. E., Physical Metallurgy Principles, second ed., Litton Educational Publishing, Inc., 1973.

[10] Voorhees, P. W., Ostwald Ripening of Two-Phase Mixtures, Annu. Rev. Mater. Sci. 22 (1992) 197-215.

[11] Sun, Z., Leibscher, C., Huang, S., Teng, Z., Song, G., Wang, G., New design aspects of creep-resistant NiAl-strengthened ferritic alloys, Scripta Mater. 68 (2013) 384-388.

[12] Storms, E. K. and Kempter, C. P., Thermal Expansion of Some Vanadium Carbides, J. Chem. Phys. 42 (1965) 2043.

[13] Storms, E. K. and Krikorian, N. H., The Variation of Lattice Parameter with Carbon Content of Niobium Carbide, N. H., J. Chem. Phys. 63 (1959) 1747-1749.

[14] Kempter, C. P. and Storms, E. K., Thermal Expansion of Some Niobium Carbides, J. LessCommon Met. 13 (2003) 443-447.

[15] Kestenbach, H. and Morales, E. V., Transmission Electron Microscopy of Carbonitride Precipitation in Microalloyed Steels, Acta Micro. 7 (1998) 22-33.

[16] Yang, Z. and Enomoto, M., Discrete lattice plane analysis of Baker-Nutting related B1 compound/ferrite interfacial energy, Mater. Sci. Eng.: A 332 (2002) 184-192.

[17] Arzt, E. and Wilkinson, D. S., Threshold stresses for dislocation climb over hard particles: the effect of an attractive interaction, Acta Metall. 34 (1986) 1893-1898.

[18] Arzt, E. and Rösler, J., The kinetics of dislocation climb over hard particles-II. Effects of an attractive particle-dislocation interaction, Acta Metall. 36 (1988) 1053-1060.

[19] Rösler, J. and Arzt, E., A new model-based creep equation for dispersion strengthened materials, Acta Metall. Mater. 38 (1990) 671-683.

[20] Mandal, S.K., Steel Metallurgy, Properties, Specifications, and Applications, McGraw-Hill, 2015.

[21] Larson, D. J., Prosa, T. J., Ulfig, R. M., Geiser, B. P., and Kelly, T. F., Local Electrode Atom Probe Tomography: A User's Guide. Springer, New York, 2013. 
[22] Gladmann, T., The Physical Metallurgy of Microalloyed Steels, Institute of Materials, London, 1997.

[23] Popov, V. V., Diffusion Parameters of Carbide Forming Elements in Fe-M-C Systems, Defect. Diffus. Forum. 283-286 (2009) 687-696. 

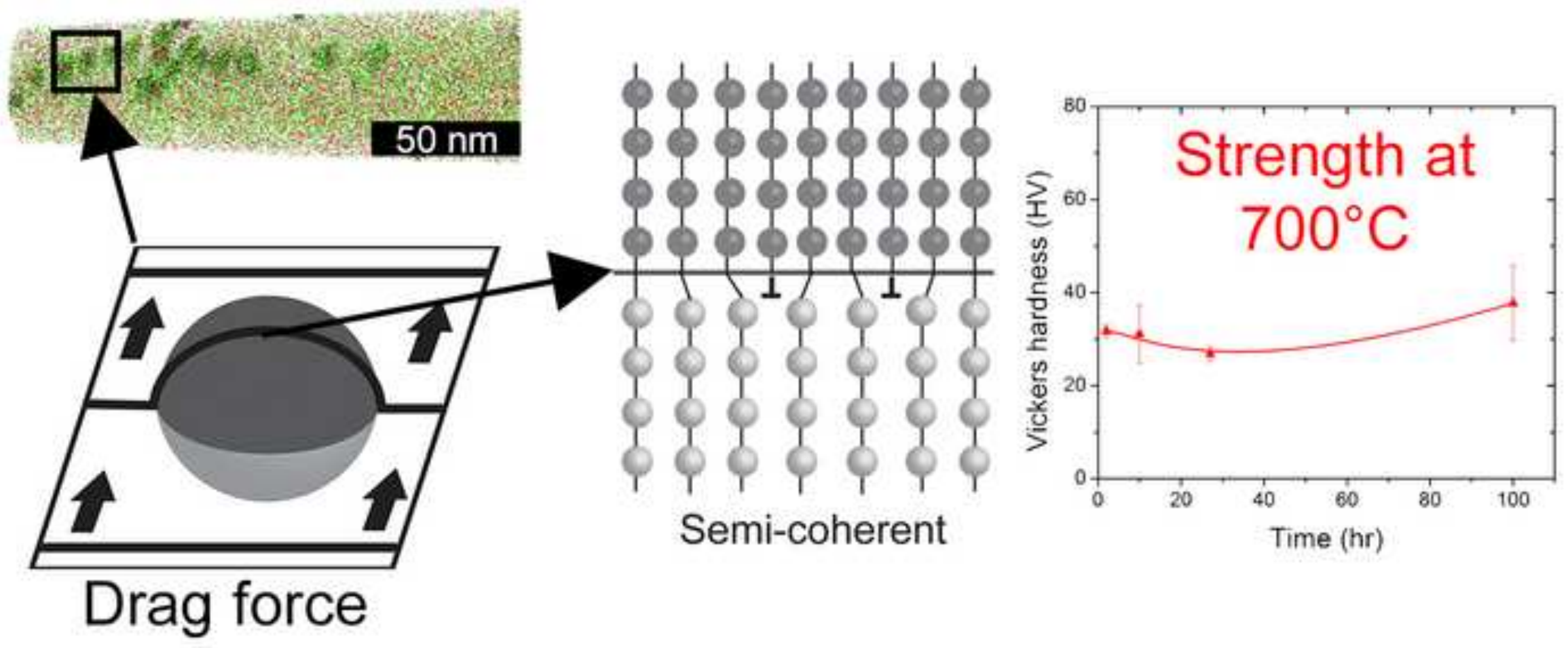

\section{Drag force}

